\title{
Retropalatal Müller grade is associated with the severity of obstructive sleep apnea in non-obese Asian patients
}

\section{Retropalatal Müller grade and OSA in non-obese}

\author{
Ming-Ju Wu • Ching-Yin Ho • Hung-Huey Tsai • \\ Hung-Meng Huang $\cdot$ Pei-Lin Lee $\cdot$ Ching-Ting Tan
}

Received: 14 June 2010 /Revised: 21 September 2010 / Accepted: 27 October 2010

(C) Springer-Verlag 2010

\begin{abstract}
Purpose The aim of this study was to investigate whether physical evaluations could be used for predicting the presence and severity of obstructive sleep apnea (OSA) in non-obese snoring patients.
\end{abstract}

This work was performed at the National Taiwan University Hospital.

M.-J. Wu

Department of Otolaryngology,

National Taiwan University Hospital Bei-Hu Branch,

Taipei, Taiwan

C.-Y. Ho

Department of Otolaryngology, Taipei Veterans General Hospital, National Yang Ming University, School of Medicine,

Taipei, Taiwan

H.-H. Tsai

College of Oral Medicine, Taipei Medical University,

Taipei, Taiwan

H.-M. Huang

Department of Otorhinolaryngology, Taipei City Hospital, Taipei Medical University,

Taipei, Taiwan

P.-L. Lee

Center of Sleep Disorder, Division of Pulmonary and Critical Care

Medicine, Department of Internal Medicine, National Taiwan

University Hospital, National Taiwan University, College of

Medicine,

Taipei, Taiwan

C.-T. Tan $(\square)$

Department of Otolaryngology, Center of Sleep Disorder,

National Taiwan University Hospital, National Taiwan University,

College of Medicine,

No. 7 Chung-Shan South Rd,

Taipei 100 Taiwan

e-mail: tanct5222@ntu.edu.tw
Methods This is a retrospective study, and a total of 244 nonobese (body mass index, BMI, $<27 \mathrm{~kg} / \mathrm{m}^{2}$ ) snoring patients (178 men and 66 women; mean age $=43.1 \pm 12.1$ years) were included. Each patient underwent polysomnography and a thorough physical examination, including flexible nasopharyngoscopy and Müller maneuver. Patients were divided into four groups based on apnea-hypopnea index (AHI) scores: normal (simple snoring), AHI $<5$; mild OSA, $5 \leqq \mathrm{AHI}<15$; moderate OSA, $15 \leqq \mathrm{AHI}<30$; severe OSA, AHI $\geqq 30$. Logistic regression was used to identify risk factors for OSA severity. Results Fifty-nine patients (24\%) were simple snorers. The prevalence of sleep apnea (mild, moderate, or severe OSA) for our non-obese snoring patients was $76 \%$. Univariate logistic analyses showed that higher BMI, male gender and retropalatal Müller grades were significantly associated with OSA severity. Multivariate logistic regression analysis identified male gender and retropalatal Müller grade as risk factors for OSA in non-obese snoring patients.

Conclusions Physical examination may be useful for studying the upper airway in non-obese snoring patients. Flexible nasopharyngoscopy with Müller maneuver appears to be useful for evaluating the severity of OSA in nonobese patients. Retropalatal Müller grade is highly related to both the presence and severity of OSA, particularly in males.

Keywords Apnea-hypopnea scale · Body mass index . Obstructive sleep apnea - Upper airway · Müller maneuver . Airway collapsibility

\section{Introduction}

Snoring is a major symptom of obstructive sleep apnea (OSA) and may be the main reason why patients with 
OSA seek medical evaluation. Patients may be simple snorers, but also have OSA. OSA patients have a high risk of developing cardiovascular and cerebrovascular disease [1].

Obesity is the most important risk factor for OSA [2]. However, OSA has become more apparent among the less obese [3]. Research performed at a single large sleep clinic in Edinburgh revealed that $50 \%$ of patients with OSA were in fact non-obese [4]. Significant exacerbations of OSA occurred in patients who were not actively treated [5], emphasizing the importance of early diagnosis and active treatment even for mild OSA.

The significance of a patient's history for predicting OSA is controversial. Pouliot et al. proposed that the Epworth Sleepiness Scale score could be used to predict OSA [6]. However; others have found no predictive value in subjectively reported daytime sleepiness in patients with OSA compared to simple snorers [7, 8]. Questionnaires regarding daytime sleepiness, fatigue and reported apnea were not able distinguish between simple snorers and individuals with OSA [9].

Pharyngeal changes, such as redundant soft palate, elongated uvula, enlarged tonsils, and oropharyngeal crowding have been reported to be associated with OSA in obese individuals [10]. However, precise physical anatomical alterations associated with OSA in non-obese adults have not been clearly established. Although polysomnography (PSG) is the standard procedure used to diagnose OSA, it is expensive and labor intensive. Use of endoscopy with Müller maneuver (MM) in the supine position has been found to reveal significant differences between snorers and non-snorers and provides a simple, inexpensive means of predicting OSA in patients who snore, regardless of weight [11]. Given this finding, we hypothesized that flexible nasopharyngoscopy with $\mathrm{MM}$ (FNMM) could also be used to predict OSA even in nonobese snoring patients.

No single factor has been identified to successfully predict OSA in the clinical setting [12]. Given that there are increasing numbers of non-obese patients with sleep-disordered breathing problems, it would be of benefit if a specific physical examination could be performed to accurately predict OSA. Despite a strong association between obesity and OSA, body mass index (BMI) does not consistently correlate with the severity of OSA as measured by the apnea-hypopnea index (AHI) [13]. In the present study, we evaluated OSA among nonobese patients and examined several clinical variables, including tonsil size, retroglossal and retropalatal size, and redundancy of uvula and soft palate, in an attempt to identify clinical risk factors for OSA before PSG testing.

\section{Methods and materials}

Patient selection

We retrospectively reviewed the medical records of consecutive patients who visited the National Taiwan University Hospital otolaryngology clinic with a chief complaint of snoring (53\% had daytime sleepiness and $32 \%$ had witnessed sleep apnea) from 2004 to 2006. Obese patients $(\mathrm{BMI} \geqq 27)$ were excluded from the study based on guidelines of the Taiwan Department of Health (http://www.doh. gov.tw/CHT2006/DM/SEARCH_RESULT.aspx).

Other exclusion criteria included abnormal lung function, such as a prescription for continuous positive airway pressure, severe cardiac failure responsible for Cheynes-Stokes breathing, upper airway neoplasm, acute rhinitis resulting in nasal obstruction at the time of the study, and central sleep apnea. A total of 244 patients met the inclusion criteria and were enrolled. Each of these patients had undergone both a thorough otolaryngological evaluation and a polysomnographic analysis (described below). This study was approved by the institutional internal review board.

\section{Polysomnography and AHI}

PSG included modified electroencephalogram (EEG) monitoring, a bilateral electrooculogram and submental, intercostal, and anterior tibialis electromyograms. Airflow was monitored by oral and nasal thermistors. Respiratory effort was monitored with chest wall and abdominal piezoelectric bands and intercostal electromyography. Cardiac monitoring was performed by modified V1 telemetry while continuous oxygen saturation was monitored by pulse oximetry. Obstructive apnea was defined as the total cessation of airflow for $\geq 10 \mathrm{~s}$ with continued respiratory effort. Obstructive hypopnea was defined as an event lasting $\geq 10 \mathrm{~s}$ that was associated with two of the following: a decrease in airflow of $50 \%$, an EEG arousal or oxygen desaturation $\geq 4 \%$. AHI was defined as the number of apneic and hypopneic events per hour of sleep.

\section{Clinical evaluations}

A complete physical examination was followed by a nose and throat examination in the sitting position, including anterior rhinoscopy, oropharyngeal evaluation and flexible nasopharyngoscopy. Nasal speculum examinations were performed with the head tilted slightly backwards to assess septal deviation, turbinate hypertrophy, nasal polyps, other masses and internal nasal pathways. The oropharyngeal evaluation included oropharyngeal crowding, tonsil size and redundancy of the uvula and soft palate. This was performed with the patients mouths widely opened and 
tongues relaxed without phonation. Tonsil size and redundancy of the uvula and soft palate were graded. Oropharyngeal crowding was determined with respect to modified Mallampati classification (MMP). Details regarding the grading of MMP, tonsils size, and redundancy of the uvula and soft palate are summarized in Table 1. Weight (kilograms, with all heavy clothing removed) was measured using digital scales (Hanson, Watford, Hertforshire, United Kingdom). Barefoot height (meters) was measured using a portable stadiometer (Holtain, Crymmych, Wales). BMI was calculated as weight $(\mathrm{kg}) /$ height $^{2}\left(\mathrm{~m}^{2}\right)$.

Flexible nasopharyngoscopy with Müller maneuver (FNMM)

Patients were examined in the sitting position using a flexible nasopharyngoscope (OLYMPUS ENF Type V, Lake Success, NY) with the pharynx in both relaxed and active states [14]. "Relaxed" was defined as normal breathing status. "Active" was defined as, with the mouth closed, the patient vigorously inhaled while an examiner occluded the nostrils. Images were recorded by computer. The FNMM procedure is summarized in Table 2. All patients were examined by the same physician (Dr. Tan).

Table 1 also summarizes retroglossal and retropalatal area sizes and Müller grading. Retroglossal and retropalatal area sizes were graded in accordance with previous reports $[15,16]$. The degrees of retroglossal and retropalatal obstructions by airway collapse when patients performed MM were calculated by computer-assisted area measurement, and used for grading retroglossal Müller and retropalatal Müller (Figs. 1 and 2). Firstly, we calculated the cross-sectional area of the retroglossal level when it was in relaxed status (Ar). Then, we calculated the same level cross-sectional area when in active status (Aa). The retroglossal Müller grade was calculated by the formula: $(\mathrm{Ar}-\mathrm{Aa}) / \mathrm{Ar} \times 100 \%$. The same method was repeated to obtain the retropalatal Müller grade. The grades in Table 1 refer to these calculated values for diminished crosssectional areas.

\section{Statistical analysis}

Results for continuous variables are given as means \pm standard deviation, and categorical variables are given as number $(n)$ and percentage (\%). In order to make comparisons between patients with varying degrees of disease severity, patients were divided into two groups based on different treatment modalities [11]. The early stage OSA group comprised patients who exhibited simple snoring and mild OSA and were kept under close observation. Patients in the advanced stage group included those with moderate and severe OSA who potentially required immediate, aggressive treatment. Continuous
Table 1 Grading systems used during physical examination

\begin{tabular}{|c|c|}
\hline \multicolumn{2}{|c|}{ Grade } \\
\hline \multicolumn{2}{|c|}{ MMP grading } \\
\hline 1 & Soft palate, pillars, and tonsils were clearly visible \\
\hline 2 & Uvula, pillars, and upper poles of tonsils were visible \\
\hline 3 & $\begin{array}{l}\text { Only part of the soft palate was visible; the tonsils, pillars, } \\
\text { and base of the uvula could not be seen }\end{array}$ \\
\hline 4 & Only the hard palate was visible \\
\hline \multicolumn{2}{|c|}{ Tonsil size grading } \\
\hline 0 & Patient had undergone tonsillectomy \\
\hline 1 & $\begin{array}{l}\text { Tonsils were in the tonsillar fossa, barely seen behind } \\
\text { the anterior pillars }\end{array}$ \\
\hline 2 & Tonsils were visible behind the anterior pillars \\
\hline 3 & Tonsils extended three quarters of the way to the midline \\
\hline 4 & $\begin{array}{l}\text { Tonsils were completely obstructing the airway ("kissing" } \\
\text { tonsils) }\end{array}$ \\
\hline \multicolumn{2}{|c|}{ Redundancy of uvula and soft palate grading } \\
\hline 0 & Not redundant \\
\hline 1 & Slightly redundant \\
\hline 2 & Markedly redundant \\
\hline \multicolumn{2}{|c|}{ Retroglossal size grading } \\
\hline 1 & Normal: allows visualization of the larynx \\
\hline 2 & Small: allows visualization of a portion of the vocal folds \\
\hline 3 & Very small: allows only a view of the posterior arytenoid \\
\hline 4 & $\begin{array}{l}\text { Obstructed: apposition of the tongue base or epiglottis to } \\
\text { the posterior pharyngeal wall }\end{array}$ \\
\hline \multicolumn{2}{|c|}{ Retropalatal size grading } \\
\hline 1 & $\begin{array}{l}\text { Normal: widely patent and may allow visualization of the } \\
\text { oropharynx }\end{array}$ \\
\hline 2 & $\begin{array}{l}\text { Small: limits view of the pharynx, but opposing walls } \\
\text { are not in proximity }\end{array}$ \\
\hline 3 & $\begin{array}{l}\text { Very small: constricted with opposing walls approaching } \\
\text { contact }\end{array}$ \\
\hline 4 & Obstructed: apposition of opposing walls \\
\hline \multicolumn{2}{|c|}{ Retroglossal and retropalatal Müller grading } \\
\hline 0 & Diminishing cross-sectional area less than $25 \%$ \\
\hline 1 & Diminishing cross-sectional area between $25 \%$ to $50 \%$ \\
\hline 2 & Diminishing cross-sectional area between $50 \%$ to $75 \%$ \\
\hline 3 & Diminishing cross-sectional area more than $75 \%$ \\
\hline
\end{tabular}

variables were compared between groups (early and advanced stage OSA) by independent two-sample $t$ tests. Corresponding categorical variables were compared by Chi-square or Fisher's exact test. Logistic regression analysis (univariate and then multivariate) was used to identify risk factors for OSA severity. A receiver operating characteristic (ROC) curve was generated to assess sensitivity and specificity. All statistical assessments were two-sided and evaluated at the 0.05 level of significance using SPSS 15.0 statistical software (SPSS Inc, Chicago, IL). 
Table 2 FNMM procedures

1. Introduced the scope via transnasal route to the level of the epiglottis

All portions of the larynx and pharynx were examined for pathology

2. Withdraw the scope to a position where the tip was in the lower oropharynx to examine the retroglossal area size

3. Asked the patient to perform MM. Firstly, inhaled and exhaled three times, then, with the mouth closed, vigorously inhaled while an examiner occluded the nostrils

Noted any tendency for the lower pharyngeal airway to collapse by motion of the tongue in a posterior direction and/or the lateral walls in a medial direction

4. Observed the supraglottic larynx for collapse over the laryngeal inlet in patients whose pharynx remained patent

5. Retracted the scope to locate the tip in the nasopharynx just cephalad and posterior to the nasopharyngeal surface of the soft palate

Observed the size of the area surrounded by the soft palate and the junction of the nasopharynx and oropharynx. We defined this as the retropalatal area

6. Repeated MM three times and evaluated the degree of airway obstruction

\section{Results}

A total of 244 patients who underwent PSG were enrolled. The demographic characteristics of these patients are summarized in Table 3 with respect to whether they had early or advanced stage OSA. For these comparisons, early stage OSA was defined as AHI $<15$, while advanced stage OSA was defined as $\mathrm{AHI} \geq 15$. These categories were based on the International Classification of Sleep Disorders [17], which reflect different risks for cardiovascular disease and needs for treatment interventions. There were significant differences between these groups for BMI, height, weight, gender, and retropalatal Müller. Advanced stage OSA patients were significantly heavier $(P<0.001)$ and had greater retropalatal Müller severity $(P<0.001)$.

Patients were further classified into four groups with respect to OSA severity based on AHI scores: normal (simple snoring), AHI $<5$; mild OSA, $5 \leqq \mathrm{AHI}<15$; moderate $\mathrm{OSA}, 15 \leqq \mathrm{AHI}<30$; and severe $\mathrm{OSA}, \mathrm{AHI} \geqq 30$ [16].

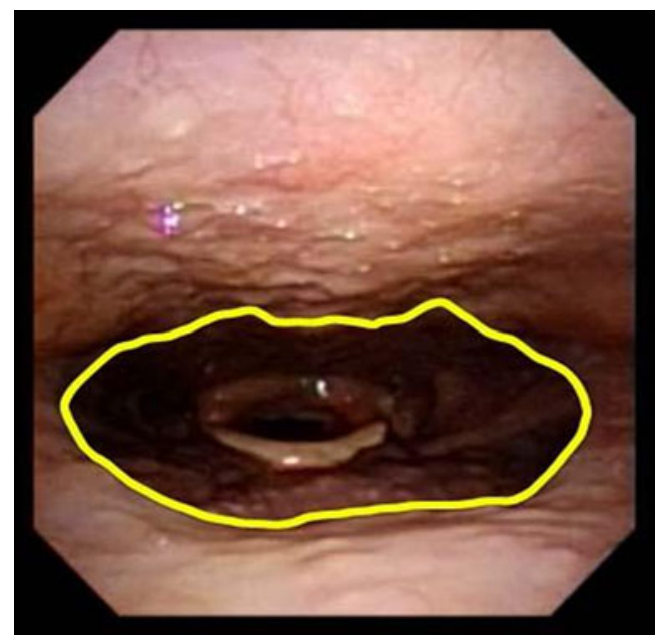

Fig. 1 Image from a representative patient showing the retropalatal area in relaxed status. Size grading, 1
Fifty-nine patients $(24 \%)$ were simple snorers. Thus, the prevalence of sleep apnea (mild, moderate or severe OSA) in our non-obese snoring patients was 76\% (185/ 244).

Univariate logistic regression analysis showed that BMI and retropalatal Müller grades were significantly associated with OSA severity in male patients; however, no factors were associated with OSA severity in females (Table 4). Subsequent multivariate logistic regression analysis identified BMI and retropalatal Müller grades as significant risk factors for developing advanced stage OSA in male patients. After controlling for retropalatal Müller, males with higher BMI were significantly more likely to have advanced OSA than those with lower BMI. Moreover, after controlling for BMI, male patients with retropalatal Müller grades of 2 and 3 were significantly

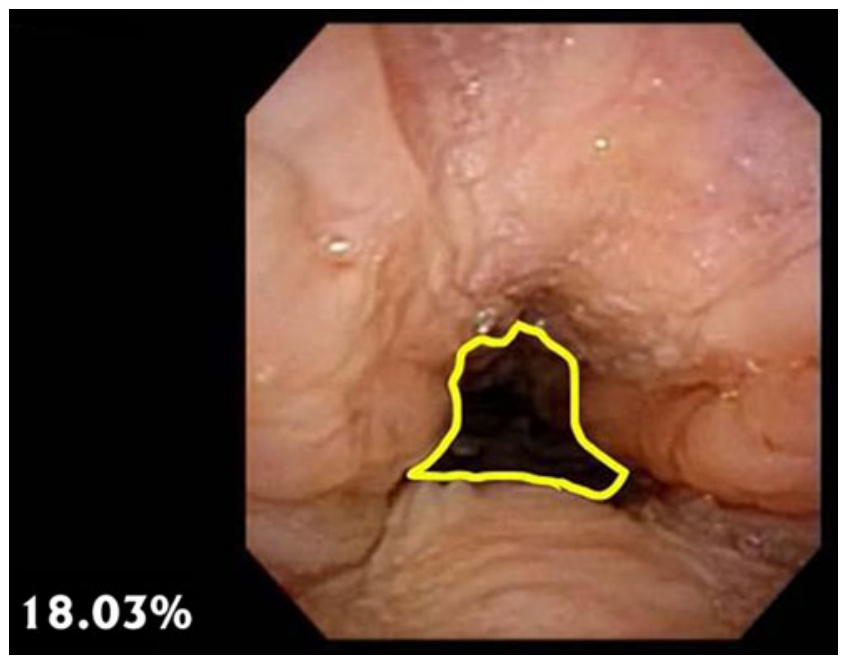

Fig. 2 Image from the same patient in Fig. 1 showing the retropalatal area in active status. Using digital image recording and computerassisted area calculation indicated that $18.03 \%$ of the cross-sectional area remained patent. The cross-sectional area diminished by $81.97 \%$. Retropalatal Müller grading, 3 
Table 3 Summary of demographic variables for patients with early and advanced stage obstructive sleep apnea (OSA, $n=244)$
Results are means \pm standard deviations or numbers (percentages)

$B M I$ body mass index, $M M P$ modified Mallampati classification $* P<0.05$, indicates a significant between group difference for a given variable

${ }^{\text {a }}$ Independent two-sample $t$ test

${ }^{\mathrm{b}}$ Chi-square

${ }^{\mathrm{c}}$ Fisher's exact test

${ }^{\mathrm{d}}$ Indicates that there were missing values for this variable

\begin{tabular}{|c|c|c|c|c|}
\hline & Total $(n=244)$ & Early OSA $(n=123)$ & Advanced OSA $(n=121)$ & $P$ value \\
\hline Age (years) ${ }^{\mathrm{a}}$ & $43.1 \pm 12.10$ & $41.6 \pm 11.57$ & $44.6 \pm 12.48$ & 0.055 \\
\hline BMI $\left(\mathrm{kg} / \mathrm{m}^{2}\right)^{\mathrm{a}}$ & $23.5 \pm 2.35$ & $22.9 \pm 2.32$ & $24.2 \pm 2.21$ & $<0.001^{*}$ \\
\hline Height $(\mathrm{cm})^{\mathrm{a}}$ & $167.4 \pm 8.06$ & $165.8 \pm 8.67$ & $169.1 \pm 7.05$ & $0.001^{*}$ \\
\hline Weight $(\mathrm{kg})^{\mathrm{a}}$ & $66.2 \pm 10.02$ & $63.3 \pm 10.19$ & $69.2 \pm 8.93$ & $<0.001^{*}$ \\
\hline \multicolumn{5}{|c|}{ Gender $\left(n(\%)^{b}\right)$} \\
\hline Male & $178(73.0 \%)$ & $71(57.7 \%)$ & $107(88.4 \%)$ & \multirow[t]{2}{*}{$<0.001^{*}$} \\
\hline Female & $66(27.0 \%)$ & $52(42.3 \%)$ & $14(11.6 \%)$ & \\
\hline \multicolumn{5}{|c|}{$\operatorname{MMP}\left(n(\%)^{\mathrm{b}, \mathrm{d}}\right)$} \\
\hline 1 & $19(7.9 \%)$ & $10(8.3 \%)$ & $9(7.5 \%)$ & \multirow{4}{*}{0.088} \\
\hline 2 & $115(47.7 \%)$ & $66(54.5 \%)$ & $49(40.8 \%)$ & \\
\hline 3 & $90(37.3 \%)$ & $40(33.1 \%)$ & $50(41.7 \%)$ & \\
\hline 4 & $17(7.1 \%)$ & $5(4.1 \%)$ & $12(10.0 \%)$ & \\
\hline \multicolumn{5}{|c|}{ Tonsil size $\left(n(\%)^{\mathrm{c}, \mathrm{d}}\right)$} \\
\hline 0 & $10(4.2 \%)$ & $7(5.7 \%)$ & $3(2.5 \%)$ & \multirow{4}{*}{0.116} \\
\hline 1 & $167(69.6 \%)$ & $87(71.3 \%)$ & $80(67.8 \%)$ & \\
\hline 2 & $59(24.6 \%)$ & $28(23.0 \%)$ & $31(26.3 \%)$ & \\
\hline 3 & $4(1.7 \%)$ & $0(0.0 \%)$ & $4(3.4 \%)$ & \\
\hline \multicolumn{5}{|c|}{ Redundancy of uvula and soft palate $\left(n(\%)^{\mathrm{b}, \mathrm{d}}\right)$} \\
\hline 0 & $35(14.6 \%)$ & $22(18.2 \%)$ & $13(11.0 \%)$ & \multirow{3}{*}{0.111} \\
\hline 1 & $47(19.7 \%)$ & $27(22.3 \%)$ & $20(16.9 \%)$ & \\
\hline 2 & $157(65.7 \%)$ & $72(59.5 \%)$ & $85(72.0 \%)$ & \\
\hline \multicolumn{5}{|c|}{ Retroglossal size $\left(n(\%)^{\mathrm{c}, \mathrm{d}}\right)$} \\
\hline 1 & $126(52.3 \%)$ & $69(56.6 \%)$ & $57(47.9 \%)$ & \multirow{3}{*}{0.311} \\
\hline 2 & $106(44.0 \%)$ & $50(41.0 \%)$ & $56(47.1 \%)$ & \\
\hline 3 & $9(3.7 \%)$ & $3(2.5 \%)$ & $6(5.0 \%)$ & \\
\hline \multicolumn{5}{|c|}{ Retropalatal size $\left(n(\%)^{\mathrm{b}, \mathrm{d}}\right)$} \\
\hline 1 & $145(60.2 \%)$ & $70(57.4 \%)$ & $75(63.0 \%)$ & \multirow{3}{*}{0.666} \\
\hline 2 & $79(32.8 \%)$ & $43(35.2 \%)$ & $36(30.3 \%)$ & \\
\hline 3 & $17(7.1 \%)$ & $9(7.4 \%)$ & $8(6.7 \%)$ & \\
\hline \multicolumn{5}{|c|}{ Retroglossal Müller $\left(n(\%)^{\mathrm{c}, \mathrm{d}}\right)$} \\
\hline 0 & $129(53.5 \%)$ & $71(58.2 \%)$ & $58(48.7 \%)$ & \multirow{4}{*}{0.096} \\
\hline 1 & $66(27.4 \%)$ & $25(20.5 \%)$ & $41(34.5 \%)$ & \\
\hline 2 & $42(17.4 \%)$ & $24(19.7 \%)$ & $18(15.1 \%)$ & \\
\hline 3 & $4(1.7 \%)$ & $2(1.6 \%)$ & $2(1.7 \%)$ & \\
\hline \multicolumn{5}{|c|}{ Retropalatal Müller $\left(n(\%)^{\mathrm{b}, \mathrm{d}}\right)$} \\
\hline 0 & $23(9.5 \%)$ & $18(14.8 \%)$ & $5(4.2 \%)$ & \multirow{4}{*}{$<0.001^{*}$} \\
\hline 1 & $50(20.7 \%)$ & $33(27.0 \%)$ & $17(14.3 \%)$ & \\
\hline 2 & $78(32.4 \%)$ & $40(32.8 \%)$ & $38(31.9 \%)$ & \\
\hline 3 & $90(37.3 \%)$ & $31(25.4 \%)$ & $59(49.6 \%)$ & \\
\hline
\end{tabular}

more likely to have advanced OSA than those with grades of 0 and 1 (OR, 2.48; 95\% CI, 1.24 and 4.98; $P=$ $0.010)$ (Table 5).

The ROC curve for non-obese male patients for developing advanced stage OSA is shown in Fig. 3. The area under the curve was $0.67(P<0.001 ; 95 \% \mathrm{CI}=0.60$ to $0.76)$. When the probability was greater than 0.60 , advanced stage OSA was predicted with a sensitivity of $72.6 \%$ and specificity of $57.7 \%$.

\section{Discussion}

It has been estimated that the prevalence of OSA in middleaged men and women is $4 \%$ and $2 \%$, respectively [18]. This increases markedly to $20 \%$ to $40 \%$ in obese individuals [19]. Obesity is the most important factor for provoking disease in many adults with OSA [2, 20]. Indeed, significant differences in BMI have been found between snoring and non-snoring individuals [11]. Ko and 
Table 4 Univariate logistic regression analysis of risk factors for developing advanced stage OSA by gender

\begin{tabular}{|c|c|c|c|c|}
\hline & \multicolumn{2}{|l|}{ Male $(n=178)$} & \multicolumn{2}{|l|}{ Female $(n=66)$} \\
\hline & OR $(95 \% \mathrm{CI})$ & $P$ value & OR $(95 \% \mathrm{CI})$ & $P$ value \\
\hline Age (years) & $2.02(0.10,1.05)$ & 0.109 & $1.04(0.98,1.09)$ & 0.196 \\
\hline BMI $\left(\mathrm{kg} / \mathrm{m}^{2}\right)$ & $1.24(1.05,1.45)$ & $0.009 *$ & $1.03(0.82,1.29)$ & 0.805 \\
\hline \multicolumn{5}{|l|}{ MMP } \\
\hline 1 & 1.00 & & 1.00 & \\
\hline 2 & $0.90(0.30,2.68)$ & 0.844 & $0.65(0.06,7.64)$ & 0.734 \\
\hline 3 & $2.19(0.69,6.92)$ & 0.183 & $0.68(0.06,8.00)$ & 0.761 \\
\hline 4 & $4.38(0.71,27.16)$ & 0.113 & $2.00(0.11,35.81)$ & 0.638 \\
\hline \multicolumn{5}{|l|}{ Tonsil size } \\
\hline 0 & 1.00 & & 1.00 & \\
\hline 1 & $3.04(0.54,17.30)$ & 0.209 & $0.73(0.07,7.80)$ & 0.732 \\
\hline 2 & $2.76(0.46,16.51)$ & 0.265 & $0.86(0.06,13.48)$ & 0.857 \\
\hline 3 & Indeterminate & 0.999 & - & \\
\hline \multicolumn{5}{|c|}{ Redundancy of uvula and soft palate } \\
\hline 0 & 1.00 & & 1.00 & \\
\hline 1 & $1.18(0.37,3.73)$ & 0.782 & $0.93(0.16,5.45)$ & 0.935 \\
\hline 2 & $1.43(0.54,3.78)$ & 1.433 & $1.32(0.29,5.99)$ & 0.720 \\
\hline \multicolumn{5}{|c|}{ Retroglossal size } \\
\hline 1 & 1.00 & & 1.00 & \\
\hline 2 & $1.56(0.83,2.93)$ & 0.165 & $2.25(0.61,8.27)$ & 0.222 \\
\hline 3 & $2.49(0.48,12.96)$ & 0.278 & Indeterminate & 1.000 \\
\hline \multicolumn{5}{|c|}{ Retropalatal size } \\
\hline 1 & 1.00 & & 1.00 & \\
\hline 2 & $1.05(0.55,2.03)$ & 0.876 & $0.27(0.05,1.36)$ & 0.112 \\
\hline 3 & $1.02(0.27,3.83)$ & 0.973 & $1.11(0.18,6.78)$ & 0.909 \\
\hline \multicolumn{5}{|c|}{ Retroglossal Müller } \\
\hline 0 & 1.00 & & 1.00 & \\
\hline 1 & $1.64(0.80,3.36)$ & 0.174 & $1.46(0.32,6.64)$ & 0.626 \\
\hline 2 & $0.74(0.33,1.63)$ & 0.449 & $0.556(0.06,5.11)$ & 0.556 \\
\hline 3 & $1.47(0.13,16.84)$ & 0.757 & Indeterminate & \\
\hline \multicolumn{5}{|c|}{ Retropalatal Müller } \\
\hline 0 & 1.00 & & 1.00 & \\
\hline 1 & $1.67(0.47,5.96)$ & 0.432 & Indeterminate & \\
\hline 2 & $2.87(0.87,9.51)$ & 0.085 & Indeterminate & \\
\hline 3 & $5.3(1.61,17.43)$ & $0.006^{*}$ & Indeterminate & \\
\hline
\end{tabular}

Results are ORs and CIs

$O R$ odds ratio, $C I$ confidence interval

${ }^{*} P<0.05$, indicates a significant risk factor of OSA among non-obese snorers in our study was that BMI was a relatively less important factor contributing to OSA, at least among males. One possible reason why the study revealed a high prevalence of sleep apnea in nonobese snoring patients might be that patients would come to a tertiary hospital only when they thought their health problem is significant.

Predisposing factors for OSA can be divided into anatomical and physical categories. Anatomically, it has been reported that the most common site of obstruction in OSA is at the level of the oropharynx [21]. Any upper airway structural abnormality may affect airway size, leading to OSA. It has been reported that OSA patients 
Table 5 Multivariate logistic regression analysis of risk factors for developing advanced stage OSA in male patients

\begin{tabular}{lll}
\hline & OR $(95 \% \mathrm{CI})$ & $P$ value \\
\hline BMI $\left(\mathrm{kg} / \mathrm{m}^{2}\right)$ & $1.21(1.02,1.42)$ & $0.026^{*}$ \\
Retropalatal Müller & & \\
0 and 1 & 1.00 & $0.010^{*}$ \\
2 and 3 & $2.48(1.24,4.98)$ &
\end{tabular}

Data are presented as ORs and CIs

$O R$ odds ratio, $C I$ confidence interval

$* P<0.05$, indicates a significant risk factor

have structurally smaller airways than normal subjects and simple snorers [22]. Along the upper airway, the retropalatal and retroglossal areas are found to be the most frequent occlusive sites [23-25]. Friedman et al. created MMP to grade oropharyngeal crowding and found that MMP and tonsil size were highly predictive for the presence and severity of OSA [10]. Schellenberg et al. reported that oropharyngeal soft tissues, including the tonsils, soft palate, uvula and tongue, played an important role in mediating airway size [13]. Given these findings, uvulopalatopharyngoplasty (UPPP) should be of benefit for snoring patients with oropharyngeal structural abnormalities. However, Sher et al. reported that the overall success rate associated with UPPP was only $40.7 \%$ in unselected patients [26]. This suggests that the tonsils, soft palate, and uvula may not play important mediating roles in some snoring patients. Therefore, it was not unexpected that we found no significant differences between the early and advanced stage groups for any of these parameters.

Nasopharyngoscopic observation of the upper airway while performing MM in awake patients with OSA was first described by Borowiecki et al. [27]. OSA patients often have a positive MM manifested by collapse of the pharynx. Subsequent studies emphasized the utility of FNMM for differentiating OSA patients from simple snorers [9, 28, 29]. As for apnea, it is related to increasing upper airway collapsibility during sleep [30]. Even in asymptomatic snorers, greater degrees of airflow obstruction are observed with increasing levels of upper airway collapsibility [31]. No previous report, however, has focused on assessing upper airway collapsibility in non-obese snoring patients. Our findings indicate that only retropalatal Müller grade was significantly different between patients with early and advanced stage OSA. Thus, physical obstructive factors would appear to be more useful for predicting OSA in nonobese snorers.

Suratt and colleagues found that a narrow airway was more likely to collapse during sleep when there was a generalized decrease in muscle tone and concluded that the pharyngeal airway of awake sleep apnea patients was more collapsible with a higher resistance than normal when subatmospheric pressure was applied [20]. The level of resistance was found to correlate with the severity of sleep-disordered breathing. In addition, Haponik et al. reported that upper airway alterations apparent during sleep in patients with OSA persisted during the daytime [32]. Furthermore, it has been found that the mechanism of obstruction observed in awake patients with OSA was similar to that observed during sleep [33]. In the present study, we examined patients awake during the daytime and found that endoscopic observation of the airway with MM was an effective, easily performed method to evaluate upper airway collapsibility and that FNMM predicted OSA in non-obese snorers.

In individuals with and without OSA, Walsh et al. found that the velopharynx (our retropalatal area) had the smallest cross-sectional area along the pharynx, and that the oropharynx (our retroglossal area) had the second smallest area [34]. Moreover, patients with OSA had a smaller than normal velopharyngeal cross-sectional area [35]. Retropalatal or retroglossal areas may be the most susceptible to collapse due to small areas. Ko and $\mathrm{Su}$ reported that the collapsing ratios of the retropalatal and retrolingual areas allowed for differentiation between snoring and nonsnoring individuals, but that only the collapsing ratio of the retropalatal area was positively correlated with RDI (equivalent to AHI in our study) and OSA staging among snorers [11]. Our results indicate that retropalatal area collapsibility could be used to differentiate patients with early and advanced OSA. Thus, the retropalatal area may be critical for influencing the development of OSA, regardless of BMI, while the degree of collapsibility of this area would appear to be associated with OSA severity.

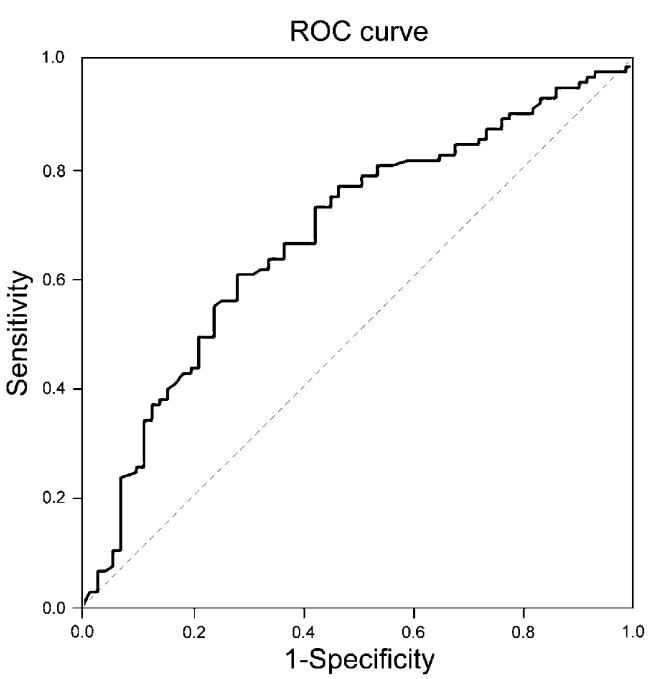

Fig. 3 Receiver operating curve (ROC) for non-obese male patients for developing advanced stage obstructive sleep apnea OSA 
With regard to assessing OSA in our study, several methodological aspects warrant further discussion. Firstly, patient relaxation is important, especially for assessing the retropalatal area, as the size of this area is frequently underestimated when first introducing the flexible nasopharyngoscope due to patient nervousness. To obtain a more accurate retropalatal area size, we first evaluated the retroglossal area and then the retropalatal area. Secondly, FNMM should be performed by a skilled, experienced physician to obtain a fixed examination location between maneuvers. Third, it is important to utilize digital image recording and computer-assisted area calculation to increase the accuracy of assessment. In this study, we focused on non-obese patients; in these patients, the retropalatal airway is usually not compromised. So when performed FNMM, the percentage of retropalatal area change could be easily evaluated. Previous assessments of retropalatal collapsibility using these methods during Müller maneuver found high predictive power when patients were supine [35]. In this study, we were able to obtain good results when we evaluated patients in an erect position.

In summary, we found that OSA prevalence in nonobese snoring patients was surprisingly high (approximately $76 \%)$. Of concern, nearly half $(49.4 \%)$ of these patients had advanced stage OSA and required aggressive treatments to prevent the development of more serious medical conditions. Not surprisingly, OSA prevalence and severity were much higher in males. Retropalatal Müller grade was found to be highly related to both the presence and severity of OSA. Our findings suggest that FNMM is an easy, fast and accurate means to assess retropalatal area collapsibility, and may be useful for determining OSA severity.

Acknowledgments Dr. Wu contributed to performing the study and manuscript writing and editing. Dr. Ho and Dr. Huang contributed to image interpretation and data analysis. Dr. Tsai contributed to statistical analysis and reference review. Dr. Lee contributed to the polysomnography analysis. Dr. Tan contributed to designing and conducting the study and manuscript editing.

Conflicts of interest The authors have no personal or financial conflicts of interest to declare

\section{References}

1. Young T, Peppard PE, Gottlieb DJ (2002) Epidemiology of obstructive sleep apnea: a population health perspective. Am J Respir Crit Care Med 165:1217-1239

2. Guilleminault C, Tilkian A, Dement WC (1976) The sleep apnea syndromes. Annu Rev Med 27:465-484

3. Gibson GJ (2005) Obstructive sleep apnoea syndrome: underestimated and undertreated. Br Med Bull 72:49-65

4. Mortimore IL, Marshall I, Wraith PK, Sellar RJ, Douglas NJ (1998) Neck and total body fat deposition in nonobese and obese patients with sleep apnea compared with that in control subjects. Am J Respir Crit Care Med 157:280-283

5. Sahlman J, Pukkila M, Seppä J, Tuomilehto H (2007) Evolution of mild obstructive sleep apnea after different treatments. Laryngoscope 117:1107-1111

6. Pouliot Z, Peters M, Neufeld H, Kryger MH (1997) Using selfreported questionnaire data to prioritize OSA patients for polysomnography. Sleep 20:232-236

7. Crocker BD, Olson LG, Saunders NA, Hensley MJ, McKeon JL, Allen KM, Gyulay SG (1990) Estimation of the probability of disturbed breathing during sleep before a sleep study. Am Rev Respir Dis 142:14-18

8. Viner S, Szalai JP, Hoffstein V (1991) Are history and physical examination a good screening test for sleep apnea? Ann Intern Med 115:356-359

9. Dreher A, de la Chaux R, Klemens C, Werner R, Baker F, Barthlen G, Rasp G (2005) Correlation between otorhinolaryngologic evaluation and severity of obstructive sleep apnea syndrome in snorers. Arch Otolaryngol Head Neck Surg 131:95-98

10. Friedman M, Tanyeri H, La Rosa M, Landsberg R, Vaidyanathan K, Pieri S, Caldarelli D (1999) Clinical predictors of obstructive sleep apnea. Laryngoscope 109:1901-1907

11. Ko MT, Su CY (2008) Computer-assisted quantitative evaluation of obstructive sleep apnea using digitalized endoscopic imaging with Muller maneuver. Laryngoscope 118:909-914

12. Deegan PC, McNicholas WT (1996) Predictive value of clinical features for the obstructive sleep apnoea syndrome. Eur Respir J 9:117-124

13. Schellenberg JB, Maislin G, Schwab RJ (2000) Physical findings and the risk for obstructive sleep apnea. The importance of oropharyngeal structures. Am J Respir Crit Care Med 162:740-748

14. Hsu PP, Tan AK, Chan YH, Lu PK, Blair RL (2005) Clinical predictors in obstructive sleep apnoea patients with calibrated cephalometric analysis-a new approach. Clin Otolaryngol 30:234-241

15. Woodson BT, Naganuma H (1999) Comparison of methods of airway evaluation in obstructive sleep apnea syndrome. Otolaryngol Head Neck Surg 120:460-463

16. Yeh PS, Lee YC, Lee WJ, Chen SB, Ho SJ, Peng WB, Tsao CC, Chiu HL (2010) Clinical Predictors of Obstructive Sleep Apnea in Asian Bariatric Patients. Obes Surg 20:30-35

17. American Academy of Sleep Medicine (2005) International Classification of Sleep Disorders, Revised. Diagnostic and Coding Manual, 2nd edn. American Academy of Sleep Medicine, Westchester

18. Young T, Palta M, Dempsey J, Skatrud J, Weber S, Badr S (1993) The occurrence of sleep-disordered breathing among middle-aged adults. N Engl J Med 328:1230-1235

19. Kyzer S, Charuzi I (1998) Obstructive sleep apnea in the obese. World J Surg 22:998-1001

20. Suratt PM, McTier RF, Wilhoit SC (1985) Collapsibility of the nasopharyngeal airway in obstructive sleep apnea. Am Rev Respir Dis 132:967-971

21. Rama AN, Tekwani SH, Kushida CA (2002) Sites of obstruction in obstructive sleep apnea. Chest 122:1139-1147

22. Isono S, Remmers JE, Tanaka A, Sho Y, Sato J, Nishino T (1997) Anatomy of pharynx in patients with obstructive sleep apnea and in normal subjects. J Appl Physiol 82:1319-1326

23. Hudgel DW, Hendricks C (1988) Palate and hypopharynx - sites of inspiratory narrowing of the upper airway during sleep. Am Rev Respir Dis 138:1542-1547

24. Trudo FJ, Gefter WB, Welch KC, Gupta KB, Maislin G, Schwab RJ (1998) State-related changes in upper airway caliber and surrounding soft-tissue structures in normal subjects. Am J Respir Crit Care Med 158:1259-1270

25. Woodson BT, Wooten MR (1994) Comparison of upper-airway evaluations during wakefulness and sleep. Laryngoscope 104:821-828 
26. Sher AE, Schechtman KB, Piccirillo JF (1996) The efficacy of surgical modifications of the upper airway in adults with obstructive sleep apnea syndrome. Sleep 19:156-177

27. Borowiecki B, Pollak CP, Weitzman ED, Rakoff S, Imperato J (1978) Fibro-optic study of pharyngeal airway during sleep in patients with hypersomnia obstructive sleep-apnea syndrome. Laryngoscope 88:1310-1313

28. Hsu PP, Han HN, Chan YH, Tay HN, Brett RH, Lu PK, Blair RL (2004) Quantitative computer-assisted digital-imaging upper airway analysis for obstructive sleep apnoea. Clin Otolaryngol Allied Sci 29:522-529

29. Santaolalla Montoya F, Iriondo Bedialauneta JR, Aguirre Larracoechea U, Martinez Ibargüen A, Sanchez Del Rey A, Sanchez Fernandez JM (2007) The predictive value of clinical and epidemiological parameters in the identification of patients with obstructive sleep apnoea (OSA): a clinical prediction algorithm in the evaluation of OSA. Eur Arch Otorhinolaryngol 264:637-643

30. Boudewyns A, Punjabi N, Van de Heyning PH, De Backer WA, O'Donnell CP, Schneider H, Smith PL, Schwartz AR (2000) Abbreviated method for assessing upper airway function in obstructive sleep apnea. Chest 118:1031-1041
31. Gleadhill IC, Schwartz AR, Schubert N, Wise RA, Permutt S, Smith PL (1991) Upper airway collapsibility in snorers and in patients with obstructive hypopnea and apnea. Am Rev Respir Dis 143:1300-1303

32. Haponik EF, Smith PL, Bohlman ME, Allen RP, Goldman SM, Bleecker ER (1983) Computerized tomography in obstructive sleep apnea. Correlation of airway size with physiology during sleep and wakefulness. Am Rev Respir Dis $127: 221-226$

33. Sher AE, Shprintzen RJ, Thorpy MJ (1986) Endoscopic observations of obstructive sleep apnea in children with anomalous upper airways: predictive and therapeutic value. Int J Pediatr Otorhinolaryngol 11:135-146

34. Walsh JH, Leigh MS, Paduch A et al (2008) Evaluation of pharyngeal shape and size using anatomical optical coherence tomography in individuals with and without obstructive sleep apnoea. J Sleep Res 17:230-238

35. Hsu PP, Tan BY, Chan YH, Tay HN, Lu PK, Blair RL (2004) Clinical predictors in obstructive sleep apnea patients with computer-assisted quantitative videoendoscopic upper airway analysis. Laryngoscope 114:791-799 